\title{
Como se posicionam os professores perante a existência e utilização de jardins zoológicos e parques afins? Resultados de uma investigação
}

António Almeida

Escola Superior de Educação de Lisboa

\begin{abstract}
Resumo
0 presente estudo insere-se numa investigação mais ampla que pretendeu verificar a incidência de concepções ambientalistas de teor antropocêntrico, biocêntrico e ecocêntrico em docentes dos diferentes ciclos de escolaridade não superior e que se envolvem em projectos de Educação Ambiental (EA). Para tal, foram entrevistados 60 docentes sobre vários assuntos relacionados com a temática ambiental, entre os quais o dos jardins zoológicos e parques afins. No tratamento dos dados, os docentes entrevistados foram divididos em dois grupos em função da proveniência de ciclos com e sem monodocência (o $1^{\circ}$ grupo foi constituído por 15 educadores de infância e 15 professores do $1^{\circ}$ Ciclo; o $2^{\circ}$ grupo, por 15 professores do $2^{\circ}$ Ciclo e 15 do $3^{\circ}$ Ciclo e Secundário). Essa divisão foi considerada especialmente pertinente para o tema em análise uma vez que os jardins zoológicos e parques afins tradicionalmente pretendem captar um público mais jovem. Assim, nos professores do $1^{\circ}$ grupo, poderia eventualmente acentuar-se mais uma conflitualidade entre o seu interesse didáctico e eventuais valores trabalhados em EA. No entanto, não se verificaram diferenças estatisticamente significativas entre os grupos em termos da incidência das diferentes perspectivas ambientalistas, tendo-se a maioria dos docentes posicionado de um ponto de vista biocêntrico, embora com uma maior frequência para o $1^{\circ}$ grupo. Perante a surpresa manifestada pelo teor da entrevista, tivemos a percepção de que os professores raramente abordam temas polémicos com os seus alunos no âmbito dos projectos de EA.
\end{abstract}

\section{Palavras-chave}

Ética ambiental - Jardim zoológico - Antropocentrismo Biocentrismo e ecocentrismo. 


\section{How do teachers stand with respect to the existence and use of zoological gardens and similar parks? Results of an investigation}

António Almeida

Escola Superior de Educação de Lisboa

\begin{abstract}
This study is part of a wider investigation that seeks to observe the presence of environmentalist conceptions of anthropocentric, biocentric and eco-centric characters among teachers from the various levels of schooling below higher education involved in projects of Environmental Education (EE). Sixty teachers were interviewed on various subjects associated to the environmental issue, among which that of the zoological gardens and similar parks. When formatting the data, teachers were split into two groups according to whether they came from levels with or without a single teacher (the first group was composed of 15 child educators and 15 teachers from the 1st cycle; the second group had 15 teachers from the 2nd cycle and 15 teachers from the 3rd cycle and secondary school). This division was considered particularly relevant to the theme under study, since zoological gardens and similar parks traditionally attempt to captivate a younger audience. For teachers belonging to the first group this could lead to increased conflict between their didactic interests and possible values developed in EE. However, no statistically significant difference was observed between the groups regarding the incidence of the different environmental perspectives; the majority of teachers exhibited a bio-centric position, although with a higher frequency in the first group. Considering the surprise with which teachers met the subject of the interview, we tend to think that they seldom approach polemic issues with their pupils within EE projects.
\end{abstract}

\section{Keywords}

Environmental ethics - Zoological garden - Anthropocentrism Bio-centrism and eco-centrism.
Contact:

António Almeida

Rua Moinho do Casalão - Casa dos

Medronheiros

2970-481 - Sesimbra - Portugal

e-mail: aalmeida@eselx.ipl.pt 
0 acentuar da presente crise ambiental, percepcionada de forma mais intensa a partir dos anos 1960, afastou do domínio da ficção a possibilidade de extinção da própria espécie humana. A gravidade da situação explica a ampla produção literária que tem vindo a alertar para os malefícios do nosso modelo de desenvolvimento e desencadeado a necessidade de repensar a postura da humanidade em relação ao planeta. Nela encontramos uma pluralidade de posições, nem sempre conciliáveis, que tendem a avaliar, de modo diferenciado, as causas e consequências da presente crise ambiental e a estabelecer uma prioridade distinta entre os diversos problemas ambientais e suas respectivas soluções.

Apesar dessa pluralidade de posições, podem identificar-se três perspectivas principais acerca do modo de conceptualizar a relação do homem com a natureza. E embora vários autores acabem por fundamentar as suas ideias através de argumentos enquadráveis em mais do que uma perspectiva, a verdade é que a maioria se insere claramente em uma delas. São elas:

- A Antropocêntrica, que defende a centralidade indiscutivel do ser humano e valoriza a natureza de um ponto de vista instrumental. Pode assumir duas tendências principais nem sempre conciliáveis. A primeira vê a natureza fundamentalmente como um recurso económico; a segunda destaca a sua importância na satisfação de uma multiplicidade de interesses que dão significado à vida humana, relevando o seu contributo para o desenvolvimento integral do ser humano em termos psicossomáticos. É nessa tendência que melhor se integra a tese da biofilia, proposta por Edward Wilson (1984), defensora de uma predisposição humana, de origem genética, impulsionadora de uma relação empática do ser humano para com os outros seres vivos.

- A Ecocêntrica, que defende o valor não instrumental dos ecossistemas e da própria ecosfera, cujo equilíbrio pode obrigar a limitar determinadas actividades humanas. E perante a condição biológica e ecológica da espécie humana, consi- dera-a parte integrante da natureza, ao contrário da afirmação dual típica do antropocentrismo. Inspira-se nas ideias de Aldo Leopold (18861948), autor da land ethic, que propôs o alargamento ético à comunidade de forma a incluir solos, água, plantas e animais, e em que a terra (land) é um sistema vivo merecedor de consideração moral. As teorizações de Baird Callicott (1989), Holmes Rolston 111 (1994) e Arne Naess (1989) são, independentemente das suas especificidades, inseridas nessa perspectiva.

- A Biocêntrica, que defende o valor intrínseco das outras formas de vida, independentemente do seu interesse para a espécie humana. Manifesta no seu seio uma importante diversidade argumentativa, podendo assumir um carácter limitado e confinado aos seres mais complexos, como no caso das teorizações de Peter Singer $(2000 ; 2006)$ e Tom Regan (1983; 1995), ou extensivo e igualitário, como no caso da de Paul Taylor (1989).

De entre os assuntos que têm sido postos a discussão com o desenrolar da presente crise ambiental, destacamos o leque de reflexões dedicado ao modo como os seres humanos se relacionam com os outros seres vivos nos mais diversos contextos. É nesse âmbito que se insere a presente abordagem acerca da existência de jardins zoológicos e parques afins.

Comecemos então por analisar os argumentos que melhor caracterizam cada uma das perspectivas ambientalistas para o tema em análise e que nos ajudam a repensar a pertinência desses espaços. Por meio dessa análise, vamo-nos aperceber como os mesmos factos podem ser sujeitos a interpretações distintas, em que uma vantagem para uma perspectiva se pode transformar num inconveniente para outra. Essa reflexão revela-se fundamental pelo facto de os jardins zoológicos e parques afins constituírem locais a que se deslocam, com frequência, professores dos diferentes ciclos de escolaridade, sendo ainda escolhidos por muitas famílias como locais de lazer e/ou educativos.

A perspectiva antropocêntrica congrega a maior parte dos argumentos favoráveis a essas 
instituições e basta pensarmos no modo como são definidas: jardins zoológicos e parques afins são locais públicos que exibem animais com as finalidades recreativa e educativa. Ainda assim, é possível serem evocadas razões características dessa perspectiva contrárias à sua existência. Salientamos a esse propósito que foi durante o lluminismo que surgiram as primeiras críticas, porque, historicamente, a manutenção de animais em cativeiro constituía um passatempo da aristocracia que por essa via afirmava o seu poder. Simultaneamente, essa excentricidade foi considerada vergonhosa, atendendo a que, ao mesmo tempo que se despendiam recursos com os animais cativos, muitos seres humanos morriam de fome (Baratay; Hardouin-Fugier, 2002, p. 73). No entanto, se essas razões podem eventualmente continuar a suscitar a adesão de algumas pessoas nos dias de hoje, são, como já afirmámos, as vantagens associadas a esses espaços que melhor caracterizam essa perspectiva. Chiszar, Murphy e lliff (apud Maple, 1995) apresentam seis dessas vantagens, que tradicionalmente se lhe encontram associadas:

1- Os zoos e aquários recebem entre 300 a 400 milhões de visitantes em cada ano, providenciando os benefícios de uma educação significativa, associada ao seu papel recreativo;

2- Os zoos têm estado tradicionalmente ligados à educação pública, e a resposta favorável dos sistemas escolares é um indicador de que valorizam essa associação;

3- Programas dedicados à sobrevivência de espécies focalizam atenção e recursos nos problemas da propagação em cativeiro de espécies ameaçadas e em perigo;

4- As mostras dos zoos reflectem uma consciência ecológica e um apoio público crescentes; 5- Uma admirável história de sucesso em trabalho clínico, ciência básica e projectos de ampla escala têm acontecido, requerendo os esforços combinados e a cooperação de muitos zoos; 6- Pelo menos doze espécies de animais foram salvas de extinção com os esforços combinados de muitos zoos do mundo.
Apesar dos argumentos antropocêntricos apresentados serem de teor não economicista, visto relevarem aspectos educacionais e científicos, importa assinalar que o elevado número de visitantes que por ano ocorrem a essas instituições (e que nos dias de hoje já ultrapassou certamente o número apresentado) possui um impacto económico não desprezável nas regiões que as possuem, apresentando-se como uma mais-valia do ponto de vista turístico.

No leque de argumentos apresentado, destacamos a referência ao papel educacional dos jardins zoológicos e parques afins, assinalado por muitos outros autores, como é o caso de Conway (1995), para quem esse potencial decorre de os zoos constituírem, com frequência, o único local que possibilita um contacto efectivo com uma diversidade de animais selvagens vivos, funcionando os animais cativos como embaixadores das suas espécies, o que impede que nos esqueçamos da sua existência. Depois, salientamos também o seu papel na defesa de espécies ameaçadas. Esse argumento, apesar de aparentemente descentrado do interesse humano, acaba por surgir invariavelmente a ele associado, dado o cepticismo das posições ecocêntricas e, especialmente, das biocêntricas acerca desse papel. Como afirma Jamieson (1995b), a maioria dos zoos dedica-se apenas à dimensão (negócio) do entretenimento e não se encontra ao serviço da preservação das espécies. Daí que gastem mais dinheiro em publicidade e relações públicas do que em programas que envolvam os animais. Eudey (1995) vai ainda mais longe nas críticas ao lembrar a existência de relatórios que implicam os zoos em aquisições ilegais de animais, acentuada quando estão em jogo espécies raras ou em extinção, o que pode contribuir para dificultar ainda mais a sua preservação. Entretanto, a questão central prende-se com o próprio sucesso dos programas de cruzamento, dado que o número reduzido de indivíduos envolvidos implica uma diversidade genética diminuta, causadora de elevada taxa de mortalidade das crias. Além disso, os animais reintroduzidos nos 
ecossistemas revelam dificuldades adaptativas, fruto do período anterior em que permaneceram em cativeiro.

Apesar dessas críticas, importa salientar que os defensores dos zoos não deixam de manifestar preocupação pelas condições de encarceramento dos animais, destacando a esse nível todo o trabalho de melhoria efectuado nos zoos nos últimos anos. Como salienta Maple (1995), os zoos modernos apostam cada vez mais na qualidade e não na quantidade de animais que possuem, oferecem recriações de habitats cada vez mais conseguidas, e preocupam-se com o bem-estar dos animais. Claro que os críticos dos zoos encaram essas melhorias como interesseiras acções de cosmética que visam essencialmente manter ou aumentar o número de visitantes, que poderia declinar perante a observância de condições chocantes de manutenção dos animais. No entanto, independentemente do grau de perversidade que possamos admitir, associado a algumas das iniciativas humanas, não é irrelevante saber, por exemplo, que por norma os seres vivos em cativeiro ultrapassam a esperança média de vida dos indivíduos da sua espécie que vivem em meio selvagem, dado que recebem assistência médica permanente, alimentação regular e não sofrem as pressões selectivas associadas à vivência ecossistémica.

Para os ecocêntricos, a questão dos jardins zoológicos e parques afins não constitui um assunto central das suas preocupações. Conway (1995) traduz de forma eloquente a secundarização desse tema pelos autores que se inserem nessa perspectiva. "É um paradoxo que tantos seres humanos se preocupem com o bem-estar de um animal, ignorando os milhões que são afectados na sua integridade diariamente através da destruição dos seus habitats" (p. 1). Para essa secundarização, não é irrelevante o seu reconhecimento de que essas instituições se têm vindo a tornar produtoras de vida e não consumidoras, recorrendo cada vez menos à captura de animais nos seus habitats e fomentando cruzamentos entre animais cativos. Ainda assim, os ecocêntricos não deixam de se posicionar sobre esse assunto, embora o façam com alguma ambivalência. Como afirma Hancocks (1995), os jardins zoológicos e parques afins, assim como os jardins botânicos, aquários e museus temáticos variados, traduzem a mentalidade do mundo ocidental, que fragmenta a realidade e fomenta o estudo compartimentado da natureza. Depois, focalizam-se quase exclusivamente nos grandes mamíferos, com destaque para os africanos, acentuando a confusão entre o tamanho do ser e o seu interesse ecológico. Por isso, afirma: "Considerando que os zoos pretendem demonstrar a riqueza e a variedade do mundo animal, apresentam uma perspectiva alarmantemente estreita” (p. 34). No entanto, não deixa em simultâneo de manifestar alguma expectativa quanto ao seu papel, principalmente se se afastarem da mera exibição de animais e fomentarem a interpretação de aspectos associados às espécies que representam; se contemplarem formas de vida mais pequenas; evidenciarem o papel funcional dos animais nos ecossistemas; promoverem uma maior especialização regional com efeitos na conservação das espécies autóctones e nas chamadas de atenção para a destruição dos ecossistemas locais. A esse nível, Loftin (1995) é taxativo:

\section{[...] de um ponto de vista da land ethic só os projectos de cruzamento em cativeiro que tenham por objectivo reintroduzir os seres em ambiente selvagem merecem apoio social. (p. 177)}

É no entanto entre os autores biocêntricos que as críticas a essas instituições são mais contundentes e movidas por razões descentradas do ser humano, começando desde logo pelo fraco entusiasmo pelas vantagens do cuidado personalizado anteriormente referidas. Para nos ajudar a compreender essa posição, Wuichet e Norton (1995) lembram que há dois critérios a considerar relacionados com a manutenção de animais em cativeiro: o do bem-estar e o da autenticidade. Ora, se no primeiro as condições de encarceramento podem ser aceitáveis ou não 
em função de critérios que procuram assegurar a integridade física e psicológica dos animais, no segundo, é o valor inerente do estado selvagem que é realçado. Nesse critério, o cativeiro em si mesmo se torna inaceitável, e nada pode compensar a perda de liberdade e das experiências autênticas vividas pelo animal no seu habitat, e que passam pela captura do seu alimento e desenvolvimento da sua própria ordem social. Para Regan (1995), os animais têm o direito a um tratamento respeitoso e não devemos reduzir o seu estatuto moral ao de meros meios para os nossos fins. Daí que a restrição da liberdade só possa admitir-se em casos em que ela seja do próprio interesse do animal, o que não acontece no caso dos zoos.

Também para Jamieson (1995a, 2006), não é o facto de alguns animais poderem viver mais tempo em cativeiro que nos diz algo acerca da sua felicidade, tanto mais que esse aumento na longevidade não deve ser generalizado se atendermos a que práticas deficientes de encarceramento conduzem a situações frequentes de canibalismo, infanticídio e luta, motivadas pela sobrelotação de algumas instalações. Entretanto, para esse autor, talvez a ideia mais gravosa transmitida pelos zoos seja a de dominação dos outros animais pelo homem, a troco de benefícios científicos e sociais diminutos. Com ela, veicula-se um falso sentido do nosso lugar na ordem natural, uma vez que os meios de confinamento acentuam a separação e a diferença entre os seres humanos e os outros animais. Nem os argumentos de Hutchins, Dresser e Wemmer (1995), de que muito se pode aprender estudando os animais cativos, especialmente se mantidos de forma mais naturalista, ou que outros tipos de pesquisa, que envolvem a recolha periódica de materiais biológicos (como sangue, urina) podem ser conduzidos mais humanamente nos zoos do que na natureza, parecem convencer os biocêntricos. Essa posição parece ser reveladora de alguma intransigência, até porque alguma investigação científica pode ser revertida a favor de outros seres das mesmas espécies estudadas. Contudo, Jamiesen (1995b) defende que se trata de uma questão de coerência: se com os seres humanos nos focamos nos indivíduos, então com os outros seres vivos temos de utilizar o mesmo critério, e não colocá-los meramente ao serviço das espécies que representam. A existência de uma dualidade de critérios é considerada pelos autores biocêntricos uma forma de especismo (justificação da preferência de seres na base de que pertencem à espécie Homo sapiens). Por essa razão, não é irrelevante saber-se o destino dado pelos zoos aos excedentes que decorrem de programas de cruzamento. Várias dessas instituições acabam por se deparar com um número de animais de que não necessitam e que se transformam num fardo financeiro. Há casos relatados da venda dos seres excedentários a instituições sem condições e até da sua morte.

A esse nivel, as teses ecocêntricas acabam por partilhar com as antropocêntricas a mesma desconsideração pela individualidade de cada animal, algo que é foco da crítica de Regan (1995), uma vez que a preocupação pelo indivíduo só surge quando a morte de um animal pode pôr em risco a sobrevivência da espécie a que pertence. Além disso, a oposição dos ecocêntricos a tudo o que perturba a diversidade, o equilíbrio e a sustentabilidade da comunidade da vida, permite o apoio à chacina de populações, quando estas ultrapassam a capacidade de suporte do sistema. Entretanto, uma vez que é inquestionavelmente a presença humana que gera efeitos adversos à diversidade, ao equilíbrio e à sustentabilidade das comunidades bióticas, Regan pergunta, de forma provocatória, por que não aplicar às populações humanas os mesmos métodos que os holistas defendem para o controlo das outras espécies.

\section{Aspectos metodológicos}

Perante uma tão grande diversidade de argumentos acerca da existência de jardins zoológicos e parques afins e da constatação de que o mesmo sucede para outros assuntos de cariz ambiental, delineamos a presente investigação que se inseriu num estudo mais amplo que pretendeu 
averiguar a incidência de concepções características das perspectivas ambientalistas já referidas antropocêntrica, biocêntrica e ecocêntrica - em professores do Ensino não Superior, a partir do questionamento acerca de vários assuntos relacionados directa ou indirectamente com a temática ambiental (Almeida, 2005).

Para o efeito, foram entrevistados os primeiros 60 docentes indicados pelos órgãos de gestão de escolas e jardins de infância dos distritos de Lisboa e Setúbal, e provenientes dos seguintes ciclos de escolaridade: 15 educadores de infância (Pré-Escolar), 15 professores do $1^{\circ}$ Ciclo, 15 do $2^{\circ}$ Ciclo e 15 do $3^{\circ} \mathrm{Ci}$ clo e Secundário, unidos pela particularidade de se encontrarem envolvidos em projectos de Educação Ambiental (EA) (Tabela 1). Esse envolvimento foi considerado fundamental, uma vez que eventuais valores trabalhados nessa área transdisciplinar, como o do respeito pelas outras formas de vida, poderiam colidir com a utilização didáctica que os professores fazem de determinados espaços: nesse caso, os jardins zoológicos e parques afins. No contacto com os órgãos de gestão, fazíamos a exigência da indicação de apenas um professor por escola, escolhido entre os que mais se destacassem na implementação de projectos de EA. Pensámos que vários professores envolvidos num mesmo projecto poderiam estar comprometidos com o mesmo sistema de valores, e essa opção assegurava, simultaneamente, uma maior dispersão da amostra. A limitação imposta não impôs qualquer constrangimento particular aos responsáveis pelos referidos órgãos, uma vez que verificámos desde o primeiro contacto serem poucos os docentes actualmente envolvidos em projectos de EA, tendo a maioria das escolas mencionado não possuir ninguém com as características pretendidas.
Fruto do processo de selecção explicado, a amostra foi constituída por professores profissionalizados com, no mínimo, sete anos de tempo de serviço, sendo os docentes do $2^{\circ}$ Ciclo e do $3^{\circ}$ Ciclo e Secundário maioritariamente licenciados em cursos de Ciências Naturais (16) e Geografia (5). Os restantes 9 possuíam licenciaturas em Agronomia, Economia, Educação Física, Filosofia, História e Filologia Românica.

As entrevistas foram realizadas nos primeiros quatro meses de 2004. A sua estrutura foi pensada em três partes distintas. Na primeira, os entrevistados registaram, em folha concebida para o efeito, alguns dados pessoais e profissionais; na segunda, responderam a 12 perguntas de resposta aberta; na terceira, foram convidados a posicionar-se perante os seguintes dez temas de forma não livre - questões fechadas: o valor da natureza, a espécie humana, a diversidade cultural, a alimentação humana, a caça, os jardins zoológicos e parques afins, os parques e as reservas naturais, o desenvolvimento económico, a poluição e o consumo de produtos ecológicos. Para cada um deles, foram apresentadas três afirmações, cada uma reflectindo uma das perspectivas em discussão - antropocêntrica, biocêntrica e ecocêntrica. Porque a diversidade teórica interna a cada perspectiva nem sempre pode ser contemplada nas diferentes afirmações, optámos, tanto quanto possível, por construir afirmações que dessem conta da ideia partilhada pelas diversas teorizações interiores a cada uma das três perspectivas em discussão. Aos professores, era pedida a ordenação das afirmações, partindo daquela com que mais se identificavam. Pedimos aos participantes que justificassem sempre a sua $1^{\text {a }}$ escolha para permitir a verificação de que a sua selecção era consistente e também para possibilitar aos professores, que não se

Tabela 1: Ciclos do Sistema Educativo Português

\begin{tabular}{|l|c|c|c|c|c|}
\cline { 3 - 5 } \multicolumn{1}{c|}{} & \multirow{2}{*}{ Pré-Escolar } & \multicolumn{3}{c|}{ Ensino Básico } & \multirow{2}{*}{ Ensino Secundário } \\
\cline { 3 - 5 } \multicolumn{1}{c|}{} & & $1^{\circ}$ Ciclo & $2^{\circ}$ Ciclo & $3^{\circ}$ Ciclo & \\
\hline Anos de escolaridade & & $1-4$ & $5-6$ & $7-9$ & $10-12$ \\
\hline Idade das crianças e dos jovens & $3-5$ & $6-9$ & $10-11$ & $12-14$ & $15-17$ \\
\hline
\end{tabular}


identificavam totalmente com a afirmação escolhida, a oportunidade de evocarem as razões por que, mesmo assim, a consideravam preferivel às outras duas, ou até avançar com outros argumentos não contemplados nas frases. A decisão de incluir questões fechadas, assim como de pedir a sua respectiva ordenação, resultou de uma cuidadosa ponderação das desvantagens e vantagens decorrentes dessa forma de questionamento. Em relação às desvantagens, assinalamos os seguintes aspectos:

- Alertam para perspectivas sobre as quais os entrevistados podem nunca ter pensado;

- Impedem a identificação nos entrevistados de ideias susceptíveis de serem enquadradas em teorizações mais específicas no seio de uma determinada perspectiva ambientalista;

- Excluem outros argumentos antropocêntricos, biocêntricos ou ecocêntricos que os entrevistados poderiam privilegiar sobre os temas contemplados;

- Obrigam a uma ordenação que pode ser considerada forçada pelos participantes quando estes partilham com igual convicção duas ou até as três ideias expressas, embora para a maioria dos temas considerados não seja provável que isso aconteça.

Em termos de vantagens, assinalamos as seguintes:

- Obrigam os inquiridos a posicionarem-se perante as ideias das diferentes perspectivas ambientalistas sem ambiguidade;

- Permitem a expressão de uma opinião (por escolha dirigida) sobre assuntos que podem não ter sido objecto de reflexão e sobre os quais, portanto, os participantes teriam dificuldade em se posicionar se sujeitos a uma pergunta aberta; - Impedem a dispersão discursiva e a fraca focalização com que muitos sujeitos tendem a responder a questões abertas;

- Tornam perceptível a consistência da resposta do participante, desde que se solicite uma justificação;
- Facilitam o tratamento das respostas em termos de investigação.

Este artigo apenas contempla a análise da questão fechada sobre os jardins zoológicos e parques afins, tendo sido as frases alternativas sobre as quais os professores tinham de se posicionar as seguintes:

A - Jardins zoológicos e parques afins são instituições fundamentais para as pessoas, particularmente os jovens, contactarem com a biodiversidade do planeta, e contribuem para a educação científica, a preservação de espécies em perigo com interesse para o homem, tendo ainda um impacto positivo no turismo.

(Afirmação antropocêntrica)

B - Jardins zoológicos e parques afins são instituições que tendem a privilegiar os animais estranhos à região onde se inserem, sem olharem também à representatividade em termos do seu papel na natureza, e só fariam sentido em articulação com a preservação de áreas naturais regionais ou nacionais afins.

(Afirmação ecocêntrica)

C - Jardins zoológicos e parques afins são instituições que servem interesses estranhos aos animais que neles se encontram, já que restringem a sua liberdade e os seus comportamentos naturais, e as recriações dos habitats apenas visam anestesiar a consciência crítica dos visitantes.

(Afirmação biocêntrica)

Da análise dessas afirmações, é fácil verificar que elas não esgotam os argumentos antropocêntricos, biocêntricos e ecocêntricos que identificámos no enquadramento teórico com que iniciámos este artigo. No entanto, uma vez que tal concretização se revelaria impossível em frases obrigatoriamente curtas, foi necessário encontrar as ideias mais representativas para cada uma das perspectivas. No caso concreto da afirmação antropocêntrica, aglutinámos argumentos de teor economicista com outros de natureza diferente; na biocêntrica, centramo-nos no critério da auten- 
ticidade; na ecocêntrica, na questão do elenco dos zoos e do seu papel nas reintroduções em áreas naturais regionais ou nacionais.

A entrevista pode ser classificada como directiva ou estandardizada, sequenciada e conduzida de forma invariável em termos da postura do entrevistador face aos entrevistados. Essas características permitiam transformá-la num questionário susceptível de ser enviado pelo correio. Entretanto, se um tal procedimento permitia um claro alargamento da amostra, a verdade é que pretendíamos respostas pessoais e espontâneas, não sujeitas a discussão com outros docentes, o que seria provável se tivéssemos enviado pelo correio vários questionários para uma mesma escola. De cada entrevista, foi feito o registo em gravação áudio para uma análise mais fidedigna das razões associadas a cada selecção. Algumas justificações dos participantes foram transcritas na integra e, de outras, apenas a parte que considerámos mais relevante para a compreensão da sua posição sobre o assunto em discussão. No entanto, procedemos ainda à correcção gramatical das frases e retirámos marcas excessivas de oralidade (incorrecções, bordões e outras idiossincrasias discursivas), mas procurando nunca alterar o sentido das frases expressas.

Para o tratamento das respostas da entrevista, considerámos dois grupos com 30 indivíduos cada: por um lado, os educadores de infância e os professores do $1^{\circ} \mathrm{Ciclo}\left(\mathrm{El}+1^{\circ} \mathrm{C}\right)$; por outro, os professores dos $2^{\circ}$ e $3^{\circ}$ Ciclos e Secundário $\left(2^{\circ} \mathrm{C}+3^{\circ} \mathrm{C}\right.$ e $\left.\mathrm{S}\right)$. A razão principal para a constituição desses grupos decorreu da diferença entre modelos de formação desses docentes (generalista no $1^{\circ}$ caso, especializado no $2^{\circ}$ ) e da consequente vivência profissional marcada pelo nível etário dos alunos com que trabalham. Partimos do princípio de que a vivência diferenciada pode acentuar ainda mais nos professores dos ciclos generalistas a conflitualidade de valores já referida, dado que pensamos que os jardins zoológicos e parques afins são particularmente visitados pelos professores desses ciclos.

Para detectar possíveis diferenças com significado estatístico, utilizámos o teste de qui- quadrado (estatística não paramétrica) para verificação da homogeneidade entre grupos no que se refere à incidência das perspectivas ambientalistas - Antropocêntrica (A), Biocêntrica (B) e Ecocêntrica (E) - para cada um dos dez temas já referidos. 0 teste foi primeiro aplicado em relação à $1^{\text {a }}$ opção escolhida. Em relação à escolha das $1^{\text {a }}$ e $2^{\text {a }}$ opções conjugadas, não foi possível a aplicação do teste de qui-quadrado utilizando o mesmo procedimento pela razão que de imediato se explica. 0 leque de possibilidade de escolha por parte dos inquiridos passou a ser o seguinte: $1^{\text {a }}$ Antropocêntrica, $2^{\text {a }}$ Biocêntrica (AB); $1^{\text {a }}$ Antropocêntrica, 2a Ecocêntrica (AE); $1^{\text {a }}$ Biocêntrica, $2^{\text {a }}$ Antropocêntrica (BA); $1^{\text {a }}$ Biocêntrica, 2a Ecocêntrica (BE); $1^{\text {a }}$ Ecocêntrica, 2a Antropocêntrica (EA); $1^{\text {a }}$ Ecocêntrica, 2a Biocêntrica (EB). Desse facto resultou uma maior dispersão das selecções dos participantes por seis pares de respostas, o que fez com que não se verificasse a condição mínima de aplicabilidade do teste ${ }^{1}$. Assim, para a constatação de diferenças entre grupos para cada tema, foi necessário considerar cada um dos pares de resposta mencionados isoladamente (por exemplo, quando um dos pares estava presente, atribuímos o valor 1; quando ausente, o valor 0). A escolha dessa via possibilitou ainda que, perante a persistência das condições de não aplicabilidade referidas, fosse possível verificarmos o valor de probabilidade a partir do teste de Fisher. 0 programa utilizado foi o SPSS (Statistical Package for the Social Sciences), e o nível de significância utilizado para os testes foi sempre para valores de $p \leq 0,05$.

Os participantes, durante a entrevista, manifestaram grande concentração na leitura das três afirmações que acompanhavam cada tema e solicitaram um ou outro esclarecimento acerca da correcta interpretação do sentido das afirmações. A ordenação efectuada pareceu assim reflectir a perspectiva real dos indivíduos. Após a entrevista, a maioria dos professores afirmou-nos que os

1. Seguimos a indicação de Conover (1999) que considera manter-se a validade do teste do qui-quadrado mesmo para valores muito baixos de frequências esperadas, desde que estas não sejam inferiores a 1. 
itens os tinham confrontado com temas e perspectivas sobre as quais nunca tinham reflectido, pelo menos de forma sistemática, e mostraram muito interesse em conhecer os resultados da investigação. Para Kahn (1999), são precisamente manifestações como essas que fazem aumentar a confiança nos dados recolhidos.

\section{Análise dos resultados}

De seguida, apresentamos os resultados referentes às respostas dos docentes dos dois grupos considerados sobre o seu posicionamento acerca dos jardins zoológicos e parques afins. A Tabela 2 apresenta a frequência de escolha das afirmações antropocêntrica, biocêntrica e ecocêntrica para a $1^{\text {a }}$ opção e para as $1^{\text {a }}$ e $2^{\text {a }}$ opções conjugadas e os valores de probabilidade resultantes da aplicação do teste de qui-quadrado. No que se refere às justificações dadas pelos professores, importa salientar que um número significativo constituiu uma mera paráfrase do teor da afirmação seleccionada. Por esse motivo, apresentamos apenas aquelas que consideramos melhor nos ajudarem a compreender a sua selecção.

Tabela 2: Incidência das perspectivas Antropocêntrica (A), Biocêntrica (B) e Ecocêntrica (C) como $1^{\mathrm{a}}$ opção isoladamente e conjugando as $1^{\mathrm{a}} \mathrm{e} 2^{\mathrm{a}}$ opções para a totalidade dos docentes e em função dos dois grupos em análise ( $\left(\mathrm{El}+1^{\circ} \mathrm{C}\right.$ e $2^{\circ} \mathrm{C}+3^{\circ} \mathrm{C}$ e S)

\begin{tabular}{|c|c|c|c|c|c|c|c|c|c|}
\hline \multicolumn{10}{|c|}{ Posicionamento face a jardins zoológicos e parques afins } \\
\hline & \multicolumn{3}{|c|}{$1^{2}$ opcẳo } & \multicolumn{6}{|c|}{$1^{2} \mathrm{e} 2^{2}$ oppöes conjugadas } \\
\hline & A & B & $E$ & $A B$ & AE & BA & BE & EA & $E B$ \\
\hline $\begin{array}{l}1^{\circ} \mathrm{G} \\
\left.(\mathrm{E})+1^{\circ} \mathrm{C}\right)\end{array}$ & 8 & 18 & 4 & 5 & 3 & 7 & 11 & 3 & 1 \\
\hline $\begin{array}{l}2^{\circ} \mathrm{C} \\
\left(2^{\circ} \mathrm{C}+3^{\circ} \mathrm{CeS}\right)\end{array}$ & 11 & 11 & 8 & 6 & 5 & 4 & 7 & 5 & 3 \\
\hline Total & 19 & 29 & 12 & 11 & 8 & 11 & 18 & 8 & 4 \\
\hline 2 & & $0=, 174$ & & $p=.739$ & $p=706$ & $\mathrm{p}=317$ & $\mathrm{p}=260$ & $\mathrm{p}=448$ & $p=612$ \\
\hline
\end{tabular}

Globalmente e no que se refere à $1^{\text {a }}$ escolha, os docentes posicionaram-se de um ponto de vista biocêntrico (29-48\%), escolhendo depois a afirmação antropocêntrica (19$32 \%$ ) e, por último, a ecocêntrica (12-20\%). Quando analisamos a tendência por grupos, verificamos que em ambos a afirmação biocêntrica foi a mais escolhida, embora o mesmo número de professores do $2^{\circ}$ grupo tenham seleccionado a antropocêntrica (onze). Simultaneamente, foram os docentes desse grupo que mais optaram pela afirmação ecocêntrica (oito contra quatro). De salientar que as diferenças entre grupos não se revelaram estatisticamente significativas ( $p=$ $0,174)$, embora esse facto, só por si, não deixe de nos suscitar alguns comentários. Quando pensamos em jardins zoológicos e outros parques afins, associamo-los a espaços privilegiados, dedicados aos mais novos. Daí termos manifestado a expectativa de um reconhecimento maior do seu interesse por parte dos docentes do $1^{\circ}$ grupo (educadores e professores do $1^{\circ}$ Ciclo), embora saibamos que as questões da biodiversidade são igualmente abordadas nas Ciências Naturais dos $2^{\circ}$ e $3^{\circ}$ Ciclos, e que vários professores desses ciclos também a eles se deslocam com o objectivo de uma observação directa das características dos animais. Apesar disso, a incidência de escolha da afirmação antropocêntrica no $1^{\circ}$ grupo não confirmou a nossa expectativa e foi mesmo superior no $2^{\circ}$ grupo como acabámos de salientar.

Quando analisamos os pares de respostas, os professores do $1^{\circ}$ grupo voltam a surpreendernos por preterirem a afirmação antropocêntrica, uma vez que onze escolheram o par BE (o que correspondeu a $61 \%$ dos que tinham optado pela afirmação biocêntrica na $1^{\text {a }}$ opção). Igual tendência manifestaram os participantes do $2^{\circ}$ grupo, tendo 7 escolhido o mesmo par (64\%). Dos 19 docentes que se posicionaram do ponto de vista antropocêntrico, o par $A B$ recebeu a preferência de onze (cinco e seis de cada grupo). A escolha da afirmação antropocêntrica seguida da biocêntrica pode parecer uma contradição, mas os docentes justificaram-na como uma tentativa para contrabalançar o interesse científico e didáctico desses locais com a salvaguarda do bem-estar dos animais. Em relação aos participantes que escolheram a afirmação ecocêntrica, o par mais escolhido foi o EA (respectivamente seleccionado por três e cinco docentes de cada grupo), o que parece apoiar a ideia de uma maior proximidade entre essas duas perspectivas para o tema em análise. Na distribuição dos pares de respostas, não se verificaram quaisquer diferenças estatisticamente significativas.

No que se refere às justificações apresentadas pelos docentes, as de teor biocêntrico 
oscilaram entre a posição convictamente contrária aos jardins zoológicos e a posição mais conciliadora que incorporou até ideias presentes na afirmação antropocêntrica. No entanto, a maioria destacou claramente o modo como os seres vivos são afectados em termos da sua qualidade de vida. Cinco docentes (quatro do $1^{\circ}$ grupo) assinalaram a infelicidade causada aos animais. Seleccionámos o exemplo seguinte que traduz bem o confronto entre o critério do bem-estar e o da autenticidade.

Quando vou ao jardim zoológico, tenho sempre a preocupação de olhar para as expressões dos animais e verificar que eles não estão felizes. Por mais tratadores que tenham e mais cuidados médicos que lhes sejam assegurados, os animais não estão felizes, não estão bem ali. $\left(\mathrm{El}+1^{\circ} \mathrm{C}\right)$

Um outro docente do mesmo grupo fez mesmo a comparação com a sua incapacidade para permanecer em espaços fechados, enquanto um outro do $2^{\circ}$ grupo expressou a sua dificuldade em visitar os jardins zoológicos.

Eu sofro um pouco de claustrofobia, e acho que os bichos também podem sofrer. E verem-se ali enjaulados, metidos num espaço mínimo, é uma tortura para eles. $\left(\mathrm{El}+1^{\circ} \mathrm{C}\right)$ Os jardins zoológicos a mim agoniam-me, não consigo, tenho dificuldade em visitá-los devido às suas condições. Aquele animal não tem nada a ver com aquilo. Ele não é dali, não faz parte daquele meio, não está no seu meio natural... 0 que é que ele está ali a fazer? Para me mostrar que existe? Para isso tenho a televisão! $\left(2^{\circ} \mathrm{C}+3^{\circ} \mathrm{C}\right.$ e $\left.\mathrm{S}\right)$

No entanto, dois dos docentes salientaram que o sofrimento se deve acentuar principalmente em algumas espécies ou classes de animais, numa preocupação pelos seres mais complexos do ponto de vista biológico. A pertinência desse argumento relaciona-se com as próprias escolhas dos jardins zoológicos e parques afins, que tendem a privilegiar mamíferos de grande porte.

Faz-me imensa confusão ver os primatas presos porque são demasiado parecidos connosco. Não me consigo meter no corpo de um crocodilo, digamos assim, e imaginar como é que pensa um crocodilo. Mas em relação a um gorila... Nós olhamos para a face deles e são muito parecidos connosco, e conseguimo-nos pôr um bocadinho dentro da pele de um gorila ou de um chimpanzé. (El $\left.+1^{\circ} \mathrm{C}\right)$

São situações profundamente plásticas e que não são naturais. Lembro-me que quando era pequenina adorava ir ao jardim zoológico. Mas depois a pessoa começa a crescer e a aperceber-se de que são situações de grande violência, sobretudo para algumas espécies. Nós vemos pássaros com pouquíssimo espaço para voar ou animais de porte elevado com áreas mínimas. $\left(2^{\circ} \mathrm{C}+3^{\circ} \mathrm{C}\right.$ e $\left.\mathrm{S}\right)$

Outra linha de argumentação manifestada por três docentes (dois do $2^{\circ}$ grupo) destacou a perda de actualidade dos jardins zoológicos e parques afins perante as possibilidades proporcionadas pelas novas tecnologias de informação. Estas permitem o conhecimento dos animais de qualquer parte do mundo, o que torna esses espaços cada vez mais obsoletos.

Os jardins zoológicos tornaram-se um absurdo, tal como a caça. Há que ser crítico em relação aos jardins zoológicos actualmente, porque eles deixaram de fazer sentido, o sentido que eventualmente possam ter tido no passado. Os poucos motivos que legitimariam a sua existência agora estão completamente ultrapassados face aos meios de que dispomos para conhecer os animais existentes no planeta. $\left(\mathrm{El}+1^{\circ} \mathrm{C}\right)$

Por último, um dos docentes foi particularmente crítico, tanto em relação ao papel educativo dos zoos como ao seu interesse associado à preservação das espécies, enquanto outros dois ma- 
nifestaram posições mais conciliadoras. Escolhemos como exemplo uma dessas posições porque expressa bem o conflito que esses espaços podem causar em alguns docentes, precisamente fruto do seu interesse didáctico.

É indiscutível que os zoos privam os animais da liberdade. Mas tenho de confessar que é uma coisa que não me faz muita confusão desde que os animais sejam bem tratados. Porque é muito agradável mostrar aqueles animais aos miúdos (risos), tenho de o confessar. Mas percebo perfeitamente que não são as condições ideais para os animais viverem. $\left(\mathrm{El}+1^{\circ} \mathrm{C}\right)$

Em termos gerais, as justificações antropocêntricas pautaram-se pelo reconhecimento das potencialidades que alguns dos docentes com concepções diferentes contestaram, pondo em destaque precisamente o valor educativo e científico desstes espaços e pouco se afastaram do teor da afirmação apresentada.

Os jardins zoológicos são uma chamada de atenção. Se o habitat daqueles animais não for protegido, no futuro só os poderemos ver ali. E há muita gente que não tem conhecimento da existência de certos animais. $\left(\mathrm{El}+1^{\circ} \mathrm{C}\right)$

Apesar dessa sintonia com as ideias expressas na frase antropocêntrica, três docentes (dois do $2^{\circ}$ subgrupo) contestaram o aspecto particular da relevância turística dos jardins zoológicos e parques afins, o que nos pareceu corresponder a um afastamento das teses antropocêntricas economicistas. Todavia, mesmo a maioria dos docentes que optou pela afirmação antropocêntrica não deixou de reconhecer espontaneamente as condições pouco abonatórias de alguns jardins, pela forma como mantêm os animais. Houve assim um consenso generalizado em relação à necessidade imperiosa de melhorar a qualidade desses espaços. Alguns salientaram ainda que a localização dos jardins zoológicos e parques afins deveria ser fora das cidades, o que possibilitaria melhorar as recriações dos habitats dos animais, aspecto indissociável do contributo para que se sintam mais livres. Ainda assim, um dos docentes considerou que o zoo de Lisboa tem melhorado significativamente nos últimos anos no modo como mantém os animais em cativeiro, opinião que não mereceu o mesmo reconhecimento da parte de um outro que se posicionou de um ponto de vista biocêntrico.

As justificações associadas à escolha da afirmação ecocêntrica pouco avançaram também ao seu teor. De destacar apenas o exercício de exemplificação de um dos docentes, que foi expresso da seguinte maneira:

Eu acho que pode ser difícil recriar determinados habitats. Por exemplo, o habitat do urso polar... É muito difícil de recriar aqui, por muito esforço que se faça. Talvez seja fácil, ou menos difícil, recriar o deserto, mas o frio polar é complicado. Portanto, se calhar, seria importante respeitar as grandes diferenças de habitat e diminuir o leque de animais do zoo. $\left(2^{\circ} \mathrm{C}+3^{\circ} \mathrm{C}\right.$ e $\left.\mathrm{S}\right)$

Em termos globais, esses resultados evidenciam a maior tendência dos docentes pela escolha de argumentos biocêntricos e ecocêntricos conjugados. Essa incidência correspondeu claramente a uma posição crítica em relação à própria existência dos jardins zoológicos e parques afins e aos moldes em que se encontram estruturados actualmente. Ainda assim, algumas justificações biocêntricas caracterizaram-se por um teor mais conciliador, o que evidencia alguma ambivalência na forma de avaliar essas instituições, fruto da conflitualidade de valores já assinalada. Essa posição crítica foi ainda mais acentuada nos docentes do $1^{\circ}$ grupo, se atendermos a que os do $2^{\circ}$ não só seleccionaram mais a afirmação antropocêntrica, como os que optaram pela ecocêntrica acabaram na sua maioria por escolher a antropocêntrica em segundo lugar.

As razões que levam os professores do $2^{\circ}$ grupo a possuir uma visão mais instrumen- 
tal dos jardins zoológicos e parques afins não se nos afigura de fácil explicação, até porque praticamente todos os educadores e professores do $1^{\circ}$ ciclo nos afirmaram já ter visitado instituições desse tipo no exercício das suas funções profissionais. Uma possibilidade explicativa pode relacionar-se com o peso maior de objectivos de natureza científica associados a essas deslocações por parte dos docentes do $2^{\circ}$ grupo, o que desde logo coincide com um dos principais argumentos dos autores antropocêntricos para a existência desses espaços. Em contrapartida, os docentes do $1^{\circ}$ grupo estariam hipoteticamente mais interessados em promover uma relação empática entre crianças e animais, o que os leva a desvalorizar alguns argumentos antropocêntricos utilitários e a uma maior identificação com a perspectiva biocêntrica, mesmo se deslocando periodicamente aos espaços em discussão.

Claro que nada sabemos acerca do modo como os docentes reflectem o seu modo de pensar os jardins zoológicos e parques afins na sua prática pedagógica. Alguns podem preferir transmitir claramente a sua posição, enquanto outros preferirão discutir diferentes argumentos que permitam a cada criança ou jovem a identificação fundamentada com uma das perspectivas. No entanto, pode também dar-se o caso de esse tema nunca ter sido objecto de discussão, situação que consideramos provável se atendermos à surpresa manifestada pelos docentes perante os temas focados ao longo da entrevista.

No que se refere à argumentação dos docentes, ela toca apenas alguns dos argumentos discutidos e associados às diferentes perspectivas apresentadas. Claro que para isso contribuiu certamente o facto de os docentes se encontrarem condicionados pelas afirmações apresentadas, o que limitou parte do seu potencial argumentativo, embora lhes tivesse sido dito que poderiam fazer os comentários que considerassem pertinentes.

\section{Consideraçōes finais}

Tradicionalmente, as opções didácticas dos professores têm sido condicionadas pelo seu po- tencial educativo. Seguindo essa linha, o que importa essencialmente verificar em relação aos jardins zoológicos e parques afins é a sua eficácia na aprendizagem científica. Daí a implementação de estudos dedicados à verificação dessa dimensão, cujos resultados podem influenciar as referidas opções. A esse nível, um estudo de Coll et al. (2003), e que obteve resultados consonantes com o de outros referidos por esses autores, faz depender a referida eficácia do próprio investimento do zoo em serviços educativos de qualidade. A articulação entre esses serviços e os professores das escolas favorece a aprendizagem dos alunos acerca dos animais e seus habitats, principalmente quando a visita se encontra articulada com os objectivos curriculares e são planeadas actividades antes e depois da sua realização. Em relação ao público em geral, o papel educativo dos zoos parece revelar-se mais limitado: os visitantes procuram essencialmente divertir-se, focalizam a sua atenção em crias e nos animais com elevada actividade ou que produzem ruído e raramente lêem a informação disponibilizada.

No entanto, ambos os públicos (escolar e geral) partilham alguma preocupação pela forma como os animais se encontram aprisionados. Coll et al. (2003) explicam como chegaram a essa conclusão, partindo do sistema de classificação de S. Campbell dos zoos em de $1^{\text {a }}, 2^{\text {a }}$ e $3^{a}$ gerações em função das características do encarceramento. Os de $1^{\text {a }}$ geração apresentam os animais em pequenas jaulas cimentadas e barradas por ferros verticais sem qualquer ligação às características dos biótopos dos animais; os de $2^{\text {a }}$ apresentam os animais em locais mais amplos separados do público através de fossas secas ou com água e incluem alguns elementos artificiais que pretendem imitar aspectos naturais dos biótopos dos animais; os de $3^{\text {a }}$ apresentam os animais em locais amplos com vegetação e formações rochosas e de solo naturais, que constituem reconstituições dos habitats. Muitos zoos têm características mistas na forma como mantêm os diferentes animais presos e, por isso, torna-se mais fácil auscultar a opinião dos visitantes acerca das condições que conside- 
ram preferíveis. Assim, a maioria dos visitantes prefere os espaços de $3^{\text {a }}$ geração, mais naturalistas, e por razões que não se prendem apenas com o facto de serem esteticamente mais agradáveis.

No entanto, a avaliação de uma instituição, actividade ou estratégia não pode apenas basearse na sua eficácia. Poderíamos admitir por absurdo que a melhor maneira de estudar seres humanos para um determinado fim seria encerrá-los em espaços limitados e impedi-los de contactar os seus familiares e amigos. Por isso, a questão assume uma dimensão ética incontornável, que obriga a discutir a própria existência dos jardins zoológicos e parques afins, mesmo reconhecendo o esforço de muitos em se tornarem espaços de $3^{\text {a }}$ geração. Jamieson (2006) sintetiza essa dimensão do seguinte modo: até que ponto a Educação necessita da manutenção de animais selvagens em cativeiro, quando esses objectivos podem ser obtidos por meio de vídeos, palestras e simulações por computador, e lança o desafio:

Não poderia a maior parte dos objectivos educacionais ser melhor atingidos através da exibição de jaulas vazias com explicações das razões por que estão vazias? (p. 136)

Este estudo permitiu concluir que parte significativa dos educadores e professores dos diferentes ciclos que trabalham em EA manifesta uma posição crítica quanto à existência dos espaços em discussão e um fraco entusiasmo pelo seu potencial didáctico. Esse aspecto revela-se em sintonia com o valor atribuído por Kellert (1997) aos diferentes tipos de experiências ligadas à natureza e que são avaliadas agora numa dimensão distinta da do seu interesse para a aprendizagem científica. Esse autor distingue entre contacto directo com a natureza: envolvimento físico com locais naturais; contacto indirecto: locais onde a natureza é gerida, como jardins e aquários; e contacto simbólico: representações veiculadas pelos media. Entretanto, para Kellert, as experiências indirecta e simbólica de contacto com a natureza não constituem alternativa à experiência directa. Na experiência indirecta, falta intimidade, desafio, criatividade e participação activa dos encontros directos com a natureza. A simbólica é uma experiência anestesiada, que ocorre no conforto do lar, e permanece incerto se permite moldar os valores das pessoas positivamente em relação à natureza. Ambas as experiências são ainda esporádicas, atípicas, altamente estruturadas, limitadoras enfim da espontaneidade, do comportamento adaptativo e do desenvolvimento de múltiplas capacidades humanas. Daí que embora os jardins zoológicos e parques afins possam desempenhar algum papel na literacia científica, se se verificar uma articulação conseguida entre os seus serviços educativos e os objectivos dos professores que a eles se deslocam, parecem contribuir de forma diminuta para o desenvolvimento psicossomático das crianças e jovens. É verdade que a argumentação antropocêntrica utilizada pelos docentes nunca admitiu essa possibilidade, mas importa acentuar a ideia de que nunca poderão ser, conjuntamente com espaços similares como aquários e jardins botânicos, substitutos adequados à vivência em espaços naturais, embora a crescente artificialização do planeta esteja a fazer perigar a possibilidade de acesso de uma população crescentemente urbana a espaços onde a natureza não é (ou é menos) gerida.

Quem já teve o privilégio de um encontro, mesmo que fugaz, com outros seres vivos em meio natural (falamos principalmente de mamíferos e aves de algum porte, à semelhança dos animais que os zoos exibem), sabe que se trata de uma experiência indescritivel do ponto de vista emocional e de uma riqueza incomparavelmente superior à dos encontros com animais que ocorrem nos zoos. Com esse argumento, estamos talvez surpreendentemente a utilizar uma argumentação antropocêntrica, à semelhança da evocada por Kellert (1997), mas agora centrada no prazer que retiramos de uma experiência. No entanto, quem sabe se essa não é uma via para a interiorização de formas de olhar os outros seres vivos de um modo menos centrado no ser humano, que conduza até à ideia de que cada vez há menos razões para que os espaços em discussão continuem a existir.

Por último, um comentário à surpresa 
manifestada pelos docentes perante os temas que incluímos na investigação descrita e entre os quais se encontravam os jardins zoológicos e parques afins. Os professores entrevistados, e que recordamos desenvolvem com frequência projectos de Educação Ambiental, pareceramnos pouco despertos para a necessidade de abordar temas polémicos, mesmo incómodos, no âmbito dessa área educativa. Tal facto surge como factor de preocupação, já que estes revelam um enorme potencial para o desenvolvimento cognitivo ao possibilitarem o contacto com diferentes posições, o que por si contribui para abanar os sistemas de crença de cada um, mexendo assim com aspectos que por vezes pensamos inquestionáveis. Como destaca Singer (2006), é verdade que as pessoas não aceitam mais as formas de encarceramento dos animais que eram comuns há 50 anos. Contudo, para esse autor, isso não impede, por exemplo, que as pessoas continuem a comprar carne de vitela, frango ou porco proveniente de animais mantidos em muito piores condições. lsso só mostra o longo caminho que a humanidade tem ainda de percorrer no sentido de aumentar a sua coerência na sua forma de relacionamento com as outras formas de vida, e como temas como a inclusão de animais na alimentação, a sua utilização e o tratamento em laboratórios, quintas, parques e reservas, e associados a actividades recreativas e desportivas, precisam também com urgência ser analisados e debatidos. Nessa medida, pensamos que uma Educação Ambiental centrada no confronto de perspectivas, e não meramente idealizada como uma área de intervenção muitas vezes tradutora de um pragmatismo irreflectido, parece-nos urgente de ser implementada. Para tal, a discussão de temas como o aqui apresentado pode constituir um importante ponto de partida.

\section{Referências bibliográficas}

ALMEIDA, A. Concepções ambientalistas dos professores: suas implicações em Educação Ambiental. 2005. Tese (Doutorado)Ciências da Educação, Universidade Aberta, Portugal, 2005.

BARATAY, E.; HARDOUIN-FUGIER, E. A history of zoological gardens in the West. London: Reaktion Books, 2002. (Publicado originalmente em francês em 1998)

CALLICOTT, B. (Ed.). In defense of the land ethic: essays in environmental philosophy. New York: State University of New York Press, 1989.

COLL, R. et al. Free-choice learning at a metropolitan zoo. In: Annual Meeting of the National Association for Research in Science Teaching, Philadelphia, 2003.

CONOVER, W. J. Practical nonparametric statistics. New York: John Wiley and Sons, 1999.

CONWAY, W. Zoo conservation and ethical paradoxes. In: NORTON, B. et al. (Eds.). Ethics on the Ark: zoos, animal welfare, and wildlife conservation. Washington; London: Smithsonian Institution Press, 1995. p. 1-9.

EUDEY, A. To procure or not to procure. In: NORTON, B. et al. (Eds.). Ethics on the Ark: zoos, animal welfare, and wildlife conservation. Washington; London: Smithsonian Institution Press, 1995. p. 146-152.

HANCOCKS, D. Lions and tigers and bears, oh no! In: NORTON, B. et al. (Eds.). Ethics on the Ark: zoos, animal welfare, and wildlife conservation. Washington; London: Smithsonian Institution Press, 1995. p. 31-37.

HUTCHINS, M.; DRESSER, B.; WEMMER, C. Ethical considerations in zoo and aquarium research. In: NORTON, B. et al. (Eds.). Ethics on the Ark: zoos, animal welfare, and wildlife conservation. Washington; London: Smithsonian Institution Press, 1995. p. 253-276. 
JAMIESON, D. Zoos revisited. In: NORTON, B.et al. (Eds.). Ethics on the Ark: zoos, animal welfare, and wildlife conservation. Washington; London: Smithsonian Institution Press, 1995a. p. 52-66.

JAMIESON, D. Wildlife conservation and individual animal welfare. In: NORTON, B. et al. (Eds.). Ethics on the Ark: zoos, animal welfare, and wildlife conservation. Washington; London: Smithsonian Institution Press, 1995b. p. 69-73.

JAMIESON, D. Against zoos. In: SINGER, P. (Ed.). In defense of animals - the second wave. Malden (MA): Blackwell Publishing, 2006. p. 132-143.

KAHN Jr., P. H. The human relationship with nature: development and Culture. Cambridge: The MIT Press, 1999.

KELLERT, S. R. Kinship to mastery: biophilia in human evolution and development. Washington: Island Press, 1997.

LEOPOLD, A. A sand county almanac. New York: Oxford University Press, 1989.

LOFTIN, R. Captive breeding of endangered species. In: NORTON, B. et al. (Eds.). Ethics on the Ark: zoos, animal welfare, and wildlife conservation. Washington; London: Smithsonian Institution Press, 1995. p. 164-180.

MAPLE, T. Toward a responsible zoo agenda. In: NORTON, B. et al. (Eds.). Ethics on the Ark: Zoos, animal welfare, and wildlife conservation. Washington; London: Smithsonian Institution Press, 1995. p. 20-30.

NAESS, A. Ecology, community and lifestyle. Cambridge: Cambridge University Press, 1989.

REGAN, T. The case for animal rights. Berkeley: University of California Press, 1983.

REGAN, T. Are zoos morally defensible? In: NORTON, B. et al. (Eds.). Ethics on the Ark: zoos, animal welfare, and wildlife conservation. Washington; London: Smithsonian Institution Press, 1995. p. 38-51.

ROLSTON III, H. Conserving natural value. New York: Columbia University Press, 1994.

SINGER, P. Libertação animal. Porto: Via Óptima, 2000. (publicado originalmente em inglês em 1990 - edição revista)

SINGER, P. (Ed.). In defense of animals: the second wave. Malden (MA): Blackwell Publishing, 2006.

TAYLOR, P. Respect for nature: a theory of environmental ethics. Princeton: Princeton University Press, 1989.

WILSON, E. Biophilia: the human bond with other species. Cambridge: Harvard University Press, 1984.

WUICHET, J.; NORTON, B. Differing conceptions of animal welfare. In: NORTON, B. et al. (Eds.). Ethics on the Ark: zoos, animal welfare, and wildlife conservation. Washington; London: Smithsonian Institution Press, 1995. p. 235-250.

Recebido em 31.01.07

Aprovado em 16.05 .08

António Almeida é professor adjunto na Escola Superior de Educação de Lisboa, Portugal, doutor em Educação Ambiental, atua no campo da Didática das Ciências e da Educação Ambiental e tem artigos e livros publicados nesses domínios. 